\title{
Processing times for English and Chinese words
}

\author{
RUMJAHN HOOSAIN \\ University of Hong Kong, Hong Kong \\ and \\ CHARLES E. OSGOOD \\ University of Illinois, Urbana, Illinois
}

\begin{abstract}
American subjects and Hong Kong Chinese subjects were asked to judge the positive/negative affective polarity of words in their respective languages. Response times were significantly quicker for Chinese, although there was no difference in latencies in simply pronouncing "positive" and "negative" in the two languages. Pronunciation durations for the English test words, however, were shorter than those for Chinese. The results are related to the alphabetic versus morphemic nature of English and Chinese, and to their difference in the requirement for phonological recoding in word processing.
\end{abstract}

Languages can be classified according to the size of the unit of writing - with the morphemic on the one hand, syllabic in between, and alphabetic on the other. In morphemic writing, each symbol represents a morpheme, the unit of meaning. (In Chinese this is usually true, with each unit called a "character" being a morpheme, although there are a few multicharacter morphemes.) Each symbol has its individual pronunciation. Thus, symbols map onto the spoken language at the morphemic level. In alphabetic writing, the symbols ("letters") represent to varying extents the phonemic units of sound in the language, and these in turn combine to form morphemes. Symbols map onto the spoken language at the phonemic level. As a common design feature, languages have many more units of meaning than units of sound. Each morphemic symbol, therefore, carries much more information than each of the two dozen or so letters of alphabetic languages. Also, processing the meanings of morphemic symbols, once they are learned, could be more direct-and therefore faster-than processing the meanings of words in alphabetic symbols. Such speculation has been made by linguists (e.g., Chao, 1968), and some empirical evidence has been reported.

Biederman and Tsao (1979), for example, reported

This research was supported by Grant NSF SOC75-00565 from the National Science Foundation and by a grant from the University of Hong Kong. Parts of this paper were presented, in Chinese, at the International Symposium on Psychological Aspects of the Chinese Language held in June 1981 at the University of Hong Kong. R. Hoosain's mailing address is: Department of Psychology, University of Hong Kong, Pokfulam Road, Hong Kong. C. E. Osgood's mailing address is: Department of Psychology, University of Illinois, Urbana, Illinois 61801 . that the Stroop effect (Stroop, 1935) is stronger for Chinese than for English. Although there are methodological problems with the study (see Hung \& Tzeng, 1981), such data would be consistent with the notion that processing of meanings of morphemic symbols is more direct. Apparently, in the Stroop test, it is more difficult for subjects to ignore the meanings of Chinese color names than it is for them to ignore the meanings of color names in English. And the perceived meanings of the color names interfere with naming the colors of the print if the color names and the colors of the actual print are different.

One aspect of the question of directness or speed of the processing of meanings of morphemic symbols is related to the role of phonological recording in language comprehension. It has been suggested that a difference between reading morphemic writing and reading alphabetic writing is that decoding to sound is not necessary for the former (Rozin, Poritsky, \& Sotsky, 1971). On the other hand, there are reports that phonological recoding is not necessary in some cases, even with alphabetical languages (Baron, 1973), but is necessary in other cases with morphemic languages (Erikson, Mattingly, \& Turvey, 1977; Tzeng, Hung, \& Wang, 1977). Obviously, the question of the effect of orthographic differences on the comprehension process still requires a lot of clarification. In this regard, it is necessary to distinguish between tasks requiring only lexical decision (as in the present study) and those involving reading of text, where it can be expected that more top-down or conceptually driven processes are involved. Hung and Tzeng (1981) made a convincing case that orthographic differences matter more in bottom-up or data-driven processes rather than in top-down processes. 
Whether the process of lexical access, arriving at the meaning of printed words, is mediated by an internal phonological representation or only by some visual representation has received a lot of attention in the literature. The dual-access model, which recognizes both "routes," is more generally accepted (McCusker, Hillinger, \& Bias, 1981). In the context of the present study, our question is whether lexical access in Chinese could be via the faster visual route (cf. Meyer, Schvaneveldt, \& Ruddy, 1974) rather than through the phonological route, and more so than possibly in the case of English in comparable tasks.

However, the nature of the actual mediational recoding mechanism is not clear. McCusker et al. (1981) reported that the diverse terminology used reveals this uncertainty; "speech recoding," "phonetic recoding," "phonological recoding," "phonemic recoding," as well as "deep phonemic recoding" have been used by various authors. Following McCusker et al., the more prudent "phonological recoding" will be used in this paper and will be taken simply to mean that the mediational representation of the printed code is related to the properties of the sounds of the language involved.

In lexical decision tasks across orthographies, the problem of comparison lies both in the design of sufficiently rapid tasks which still provide detectable and reliable differences and in the isolation of central meaning processes from peripheral perceptual (seeing) and response (saying) processes. For example, testing in different languages usually requires verbal responses in the respective languages, which involve different articulatory or acoustic characteristics, which in turn affect measured response times. The present study reports clear differences in the processing speeds for Chinese versus English, which can be attributed to central meaning processes rather than to peripheral processes. Furthermore, it seems that the results could be related to differences in the requirement of phonological recoding in the comprehension of words in the two languages.

\section{EXPERIMENT 1}

\section{Method}

Stlmull. The universal bipolar semantic nature of the affective meanings of words, for example, angel-devil, clever-stupid, winlose (Boucher \& Osgood, 1969; Greenberg, 1966), makes possible a simple cross-linguistic task by asking subjects to judge the affective polarity of presented words. The English items used were 30 pairs of antonyms (see Appendix) consisting of nouns, verbs, adjectives, etc. The Chinese items were translations of the English items (see Osgood, 1980, for the actual Chinese items used). Both the English and Chinese items averaged 1.9 syllables (i.e., the Chinese items averaged 1.9 characters). Also, both English and Chinese items averaged 4.1 phonemes. Efforts were made to match the overall frequencies of usage of positive versus negative English words according to Kučera and Francis (1967). However, there is no comparable frequency count for Chinese items. Therefore, efforts were made to match the overall subjective frequency esti- mates for the positive versus negative Chinese items, according to the procedures of Carroll (1971). Since the items used were rather common words in both languages, we might assume that their respective frequencies in English and Chinese are generally comparable.

Subjects. There were two groups of subjects, each tested in their own language. The first group consisted of 18 undergraduates from the subject pool at the University of Illinois. The second group was made up of 20 volunteer undergraduates at the University of Hong Kong.

Apparatus. The experimental items were presented by slide projection on a screen in front of the subject. When each word appeared, a photo-cell activated a timer; when the subject said either "positive" or "negative" (or their Chinese equivalents, which are both monosyllabic), the timer was stopped via a voice-operated relay.

Procedure. The subjects were tested individually and were presented individual items from the 30 pairs of antonyms in the appropriate language, in random order, with the constraint that words with opposite meanings could not appear within three words of each other. When a word appeared on the screen, the subject's task was to decide as quickly as possible whether it meant something positive or negative, and accordingly to respond by announcing "positive" or "negative" [or their Chinese (Cantonese) equivalents] to stop the timer. There were six practice items.

It is obvious that in this task subjects would have to (1) look at the presented item, (2) process certain aspects of its meaning, (3) decide whether that meaning was affectively positive or negative, and then (4) simply say "positive" or "negative." The first and last processes are peripheral, taking place between the eyes and the sensory cortex and between the motor cortex and the vocal muscles, respectively; the intermediate ones are central meaning processes. If phonological recording is required in this wordprocessing task, it should take place between stages (1) and (3).

To get some estimate of the peripheral (seeing) and response (saying) times-with no central meaning processes involved-the subjects were given a pretest before the experiment proper. They were shown the words "positive" or "negative" (or the Chinese equivalents for the Chinese subjects) in random order 10 times each. Each time, the subject was simply to pronounce whichever word was shown. It is assumed that completion of these repetitious pronunciation tasks did not require central meaning processes. This does not mean to imply that no mental process is needed for the pronunciation task - it should be clear, however, that the role of central processes in terms of required processing times should be much less.

\section{Results and Discussion}

Table 1 shows that, for Chinese (pronounced in the Cantonese dialect), the average time for seeing and saying "positive" was quicker than it was for seeing and saying "negative" ( $p<.02$ by sign test). For English, it was quicker for "negative" (also, p < $.02)$. The mean difference was not more than $20 \mathrm{msec}$ in each case, and was probably due to articulatory or acoustic differences between saying the two words in

Table 1

Peripheral Response Times (in Milliseconds) for "Positive" and "Negative," and Total Response Times for Positive and Negative Words in English and Chinese

\begin{tabular}{lcccc}
\hline & & & \multicolumn{2}{c}{ Total Response } \\
& & & $\begin{array}{c}\text { Positive } \\
\text { Test Words }\end{array}$ & $\begin{array}{c}\text { Negative } \\
\text { Test Words }\end{array}$ \\
\hline English & 498 & 479 & 964 & 1045 \\
Chinese & 486 & 503 & 806 & 923 \\
\hline
\end{tabular}


the respective languages (e.g., "negative" in Cantonese and "positive" in English both begin with labials). When averaged across "positive" and "negative," however, these peripheral "seeing" and "saying" times for English compared with Chinese were not significantly different. That these pronunciation tasks did not require central meaning processing is indicated by their much shorter latencies as compared with those for judging the affective polarities of individual test words in the respective languages, also shown in Table 1-although identical overt responses were produced.

The percentages of errors (incorrect responses of "positive" or "negative") were $3.1 \%$ and $2.3 \%$, respectively, for English and for Chinese. The response times for individual "error" responses were ignored in subsequent analyses.

For both languages, positive words had much faster processing times than negative words, when these included both peripheral and central (meaning) processing $(t=3.84, p<.001$, for English; $t=5.94, p<.001$, for Chinese). This is consistent with the assumption that meanings of positive and negative words are derived via their associations with "approach" and "avoidance" behaviors, respectively (cf. Hoosain, 1977; Osgood, 1971). When response times for all 60 translation equivalents were compared, Chinese yielded faster times by an average of $140 \mathrm{msec}(t=9.74, p<.0001)$. That this was due to differences in central meaning processes is evident from the fact that the peripheral times were about the same for the two languages. This pattern of results also suggests that factors such as the motivation of the two groups of subjects or the speeds of pronunciation of the English versus Chinese responses were probably not material.

\section{EXPERIMENT 2}

While the results of Experiment 1 support the notion that comprehension of morphemic symbols is faster than that of alphabetic symbols, they do not necessarily implicate the difference in the requirement of phonological recording as the factor involved. Experiment 2 was designed to investigate some aspect of the times required for phonological recording of the experimental items in English and Chinese. The reasoning was that, if we compare the "normal" reading or pronunciation times for the words in the respective languages, we should have some idea of the relative times required for the mechanism of phonological representation, since the latter is supposed to be relative to the pattern of sounds in the two languages.

\section{Method}

Three native English speakers and four native Cantonese speakers, all recent graduates of psychology, were asked to read a list of the 60 experimental items in random order in the appropriate language. They were asked to pronounce the items on the list "naturally" at the rate of about one item a second. Each subject's reading was recorded, and the tape recording was processed by a Siemens Mingograph. The sound duration of each pronunciation of the 60 words was measured.

\section{Results and Discussion}

Table 2 shows the mean sound duration and the standard deviation of the durations for each subject's pronunciation of the 60 experimental items. It is clear that the durations were markedly different for the two languages. For English, the mean across the three subjects was $245 \mathrm{msec}$, and for Chinese the mean across the four subjects was $472 \mathrm{msec}$. In this connection, it should be recalled that the English and Chinese items have about the same averaged syllabic as well as phonemic length. But the Chinese "words," being of an average of 1.9 syllables or characters long, are mostly made up of two separate visual entities (characters), unlike two-syllable English words. In other words, the Chinese characters form two Gestalt wholes at the level of sensory integration (cf. Osgood \& Hoosain, 1974), rather like English nominal compounds such as "post card." It could be these separate Gestalt wholes that prolong the pronunciation durations of the Chinese items.

\section{DISCUSSION}

We have clear evidence that the processing of some aspects of meaning of Chinese words is faster than that of English words. This difference is, furthermore, not related to any peripheral perception and response processes. It should be noted that the peripheral perception and response times for English and Chinese were comparable. It was only when perception of meaning was involved that response times for Chinese became faster. The peripheral response times provide a baseline for comparing the two groups of subjects. Otherwise, the question would arise as to whether motivational and other characteristics of the American and the Chinese subjects were comparable.

There is an indication that the subjects processing the Chinese words did not require the same kind of phonological recoding that was required for English.

\section{Table 2}

Pronunciation Duration Times (in Milliseconds) for English and Chinese Words

\begin{tabular}{cccccc}
\hline & \multicolumn{2}{c}{ English } & & \multicolumn{2}{c}{ Chinese } \\
\cline { 2 - 3 } \cline { 5 - 6 } Subject & Mean & SD & & Mean & SD \\
\hline 1 & 223 & 91 & & 472 & 159 \\
2 & 283 & 118 & & 463 & 119 \\
3 & 228 & 116 & & 521 & 114 \\
4 & & & & 420 & 129 \\
Means & 245 & & & 472 & \\
\hline
\end{tabular}


The times required for phonological recoding, of course, could not be identical to normal durations for actual pronunciation. But we would expect that if similar mechanisms of phonological recoding are required in the two languages, the processing times in Experiment 1 should bear some relation to the relative pronunciation duration times for the two languages in Experiment 2. This would mean that processing times for Chinese should be longer.

It is conceivable that, independent of orthographic differences, Chinese culture emphasizes positive/ negative polarity of things, and therefore the Chinese subjects were more ready to make positive/negative decisions. However, given that affective polarity is a language universal (cf. Osgood, May, \& Miron, 1975) and given the lexical decision nature of the experimental tasks, it is probably unlikely that cultural or personality factors produced the difference in the two groups of subjects. The numbers of "errors" produced by the two groups of subjects were also not significantly different.

The explanation of the difference between Chinese and English would have to be based on the directness of the processing of meaning of morphemic symbols. In connection with the dual-access model, it would seem that, at least in the present task, the visual route is more available to the Chinese subjects than it is to the American subjects. We might also relate the present findings to some of the those previously reported. We have noted that although some studies found differences between Chinese and English, others did not. What might be useful in clarifying the reported data on this topic could be some notion of levels of processing of meaning. Features of affective meaning have been noted as pervasive and dominating in much of human behavior, including language (Osgood, 1971). Possibly, in processing visual or linguistic signs, these affective meanings are among the earlier aspects of meaning that are reacted to by subjects. And, in the case of Chinese-with symbols mapping onto the spoken language at the morphemic level-it is easier to notice such aspects of meaning without access through the phonological route.

In the present experiment, a decision on the affective meaning of presented items was all that was required, and subjects did not need to consider other aspects of meaning. In the Biederman and Tsao study (1979), any aspect of conflict of meaning (including affective meaning) would produce the Stroop effect. In studies reporting a lack of difference between morphemic and alphabetic languages, on the other hand, what appear to be involved are meanings of signs beyond affective polarity (e.g., grammatical appropriateness). It could be that, when more manifest aspects of meaning are involved, morphemic symbols are processed directly (that is, through the visual route rather than the phonological route), whereas, in other cases, orthographic differences are superceded by common requirements of phonological recoding to facilitate deeper lexical access. This explanation assumes some hierarchy of availability of meaning (cf. Collins \& Quillian, 1969), or the distinction between bottom-up and top-down processes.

A recent study by Treiman, Baron, and Luk (1981) appears to contradict the above suggestion. In a sentence-verification task (e.g., to decide whether Coal/Lead is a kind of plant is true or false), Chinese sentences containing a homophone word, such that the sentence would sound true if read aloud, resulted in less impairment relative to controls than did similar English sentences with homophones. This is taken to mean that speech recoding is used less in Chinese, even at the level of sentence processing. But it should be noted that the sentences used were so simple that, effectively, truth/falsity could be decided simply by comparing two stimulus words (e.g., coal/lead and plant, or even just the radicals comprising these Chinese characters). Thus, the task did not need to be a complex sentence verification task, but could be, in effect, one of perception of the simple meanings of two individual morphemic symbols.

\section{REFERENCES}

Baron, J. Phonemic stage not necessary for reading. Quarterly Journal of Experimental Psychology, 1973, 25, 241-246.

Biedenman, I., \& Tsao, Y. C. On processing Chinese ideographs and English words: Some implications from Stroop-test results. Cognitive Psychology, 1979, 11, 125-132.

Boucher, J., \& Osgood, C. E. The Pollyanna hypothesis. Journal of Verbal Learning and Verbal Behavior, 1969, 8, 1-8.

Carrolr, J. B. Measurement properties of subjective magnitude estimates of word frequency. Journal of Verbal Learning and Verbal Behavior, 1971, 10, 722-729.

Снмо, Y. R. Language and symbolic systems. Cambridge: Cambridge University Press, 1968.

Collins, A. M., \& Quillian, M. R. Retrieval time from semantic memory. Journal of Verbal Learning and Verbal Behavior, $1969,8,240-248$.

Erickson, D., Matringly, I., \& Tunvey, M. Phonetic activity and reading: An experiment with kanji. Language and Speech, $1977,20,384-403$.

Greenbera, J. H. Language universals. In T. A. Sebeok (Ed.), Current trends in linguistics: III. Theoretical foundation. The Hague: Mouton, 1966.

Hoosaln, R. The processing of negative or incongruent perceptual and combined perceptual/linguistic stimuli. British Journal of Psychology, 1977, 68, 245-252.

Hung, D. L., \& Tzeng, O. J. L. Orthographic variations and visual information processing. Psychological Bulletin, 1981, 90, $377-414$

Kučera, H., \& Francis, W. N. Computational analysis of present day American English. Providence, R.I: Brown University Press, 1967.

McCusker, L. X., Hillinger, M. L., \& Bias, R. G. Phonological recoding and reading. Psychological Bulletin, 1981, 89, 214-245. 
Meyer, D. E., Schyaneveldt, R. W., \& Ruddy, M. G. Functions of graphemic and phonemic codes in visual word recognition. Memory \& Cognition, 1974, 2, 309-321.

Osgood, C. E. Exploration in semantic space: A personal diary. Journal of Social Issues, 1971, 27, 5-64.

Osgood, C. E. Lectures on language performance. New York: Springer-Verlag, 1980.

Osgoon, C. E., \& Hoosain, R. Salience of the word as a unit in the perception of language. Perception \& Psychophysics, $1974,15,168-192$.

Osgood, C. E., May, W. H., \& Miron, M. S. Cross-cultural universals of affective meaning. Urbana: University of Illinois Press, 1975.

Rozin, P., Ponitsky, S., \& Sotsky, R. American children with reading problems can easily learn to read English represented by Chinese characters. Science, 1971, 171, 1264-1267.

STroop, J. R. Studies of interference in serial verbal reactions. Journal of Experimental Psychology, 1935, 18, 643-662.

Treiman, R. A., Baron, J., \& LuK, K. Speech recoding in silent reading: A comparison of Chinese and English. Journal of Chinese Linguistics, 1981, 9, 116-125.

Tzeng, O. J. L., Hung, D. L., \& Wang, S. Y. Speech recoding in reading Chinese characters. Journal of Experimental Psy. chology: Human Learning and Memory, 1977, 3, 621-630.
APPENDIX

\section{English Experimental Items}

$\begin{array}{llll}\begin{array}{l}\text { proud } \\ \text { shameful }\end{array} & \text { joy } & \text { wonderful } & \text { reward } \\ \text { pain } & \text { terrible } & \text { punish } \\ \text { rejoice } & \text { gain } & \text { kind } & \text { win } \\ \text { regret } & \text { loss } & \text { cruel } & \text { lose } \\ \text { trust } & \text { tall } & \text { careful } & \text { praise } \\ \text { doubt } & \text { short } & \text { careless } & \text { blame } \\ \text { victory } & \text { fertile } & \text { true } & \text { advance } \\ \text { defeat } & \text { barren } & \text { false } & \text { retreat } \\ \text { angel } & \text { clever } & \text { positive } & \text { encourage } \\ \text { devil } & \text { stupid } & \text { negative } & \text { discourage } \\ \text { success } & \text { merciful } & \text { rich } & \text { hire } \\ \text { failure } & \text { merciless } & \text { poor } & \text { fire } \\ \text { heaven } & \text { fragrant } & \text { enjoy } & \text { admire } \\ \text { hell } & \text { odious } & \text { suffer } & \text { despise }\end{array}$

happiness tidy misery messy

(Manuscript received April 20, 1982;

revision accepted for publication August 30, 1983.) 